\title{
In the Covid-19 Regime - What Role Intellectual Society Can Play
}

\author{
Bhandari Medani Prasad $1,2,3,4$
}

\author{
${ }^{1}$ Akamai University, Hawaii, USA \\ ${ }^{2}$ Sumy State University, Ukraine \\ ${ }^{3}$ The Equality Foundation, USA \\ ${ }^{4}$ Human Survival Foundation, UK
}

Received: 07.09.2020; Accepted: 11.10.2020; Published: 20.12.2020

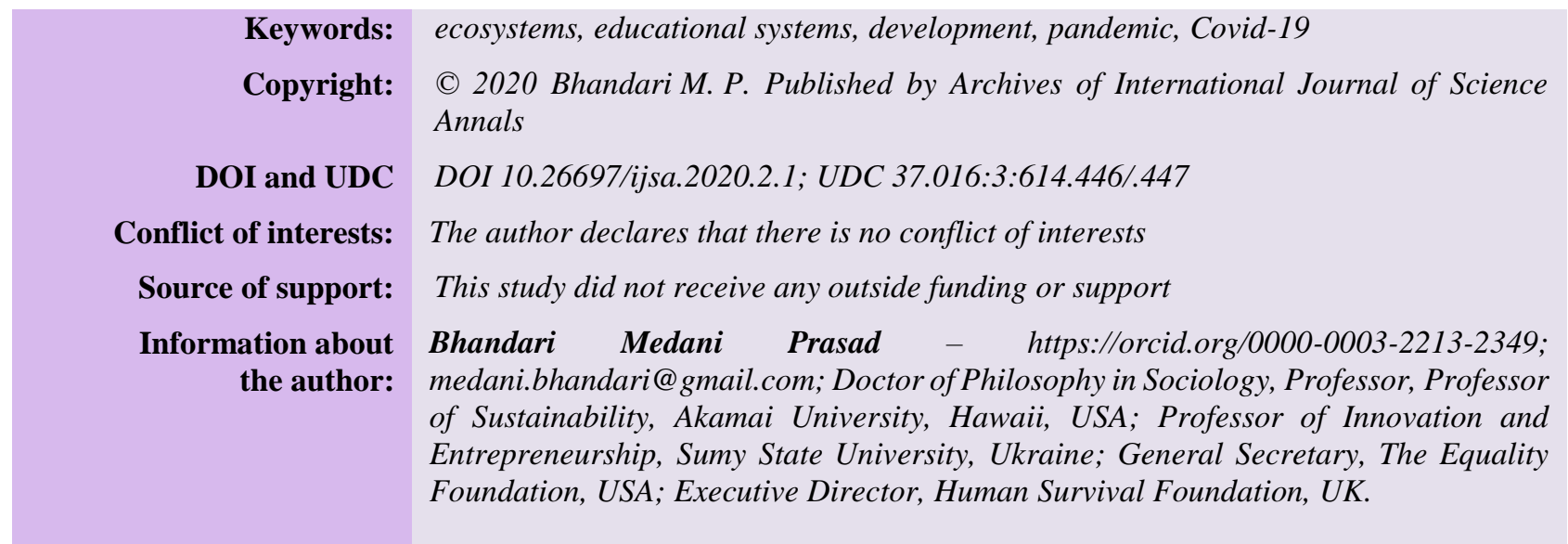

The contemporary world is in very difficult trajectory. As a matter of fact, the Humanity is in crisis and in challenge. The scholarly world is also kind of traumatized. We all are scared due to uncertainty created by the Corona Pandemic. Covid-19 pandemic has created great uncertainty humanity has ever faced and its impact is everywhere, over the economy, employment, finances, relationships, and physical and mental health as well as in social equilibrium.

When there is crisis, it is normal to lose patience, perseverance and the mental strength, and also there is always a chance of hopelessness. As such we live in hope and hope creates the motivation to move ahead. Motivation creates inner power to human heart as well as in the human brain. The current crisis has direct impact to all of us and we are in the crisis of humanity, and even crisis is hope as well as crisis of motivation. Our regular thinking pattern is deeply disturbed, our regular living style is altered, our all collegial circles are under confusion and also in suspicious condition within and beyond. When there is a direct hit on human brain due to uncertainty and fear, it raises direct pain in the deep-thinking pattern and when there is danger around us, we may begin to think everything differently. At present our condition is instable therefore, our creativeness, is disturbed, and the established notion of research, development, innovation and contribution to the society at large is also in danger cloud.
In my opinion, at this crisis, to some extent, we are facing abnormality - within ourselves, in societies, and it has spread to social, educational, institutional, political, economic, religious patterns as well as in our deep root of knowledge, wisdom patterns. This abnormality has directly impacted the hope foresee route. At the same time, when danger surrounds us, it is hard to remain calm, peace. This disturbance directly hits the knowledge production pattern. Even Having this situation, if we are able to produce the scholarly papers (knowledge), that means, we are still very strong, we have hope and power of tolerance of uncertainty.

As a lay person of the society and a student of social science, I believe that togetherness, unity, humanly feelings of connectedness within us and beyond, empowers us to be strong and provides the power of tolerance. When we feel that "I am" "we are" not alone, and feel that, we are not only in trouble, that gives an unseen power to look ahead, and prepare for the extreme events, crisis, etc. we may have to face again and again. The Covid-19 is the example of extreme crisis. Here, I would like to share, my feeling and thoughts that, it is just the beginning of Corona impact. As we already know that, it has created untrusty environment especially to the political system (administration). We are noticing various tensions, between governments, governments and citizens or victimized general public. 
The innocent poor, people are being victimized without there any role to spread the virus.

Furthermore, it is hard to forecast, what kind of devastating impacts are on the way. It is already noticed that countries economic conditions are already began to collapse. There is strong chance of another global economic recession and it may take several years to overcome from this foreseeable economic recession. We have already seen that, how much the airlines industries, tourism, hotel, recreational industries are suffering. The productional industrial sectors are also in trouble and unemployment is raising almost in every countries of the world. The main, responsible sector - the health system is not being able to cope with the pandemic spread.

These situations have direct impact on our educational systems of all levels. The research agendas are shifted and there is financial scarcity on research and development fields. In this situation, producing knowledge, writing research papers is not easy. However, now, we researchers, and educators have more responsibilities. Because we know the meaning of knowledge, wisdom, innovation, discovery, invention. Therefore, it is our responsibility to produce more knowledge and distribute more which can show that the intellectual world is still active. This activeness of scholarly world can help to maintain hope and motivation within and beyond the academic scholarships. To some extent, we can state that knowledge creates hope.

Through this note, I would like to urge/request to all educators, scholars, scientists and to all other knowledge related stakeholders of the globe, that, the knowledge creators and educators should not stop our research and our contribution to the society. The world has been facing crisis throughout its development processes and the world has already witnessed many pandemic crisis as well as other kind of crises, of many types even apolitical, political, economic, social, psychological, ethnic, gender, race, color, (human created) or natural disasters, which had completely changed the face human civilizations. However, mostly, the saviors have been always the knowledgeable persons or change makers who never stopped working fearlessly. As such we should acknowledge ourselves that, we are the knowledge creators, wisdom generators of the society; therefore, one way or another we are also hope creators; beauty admires, and love and respect maintainers. We should take our responsibility in a way that other stakeholders also realize that, this is not the end of the world and they also need to feel that, together we can bear the risk, tolerate the uncertainty and maintain the hope of anxiety free world.

Here, I would like to state that, as knowledge creators, educators and responsible citizens of this planet, we need to think, how this world can be better place for all of us including all living species of the various ecosystems.

There is term or an idea of Bashudhaiva Kutumbakam (meaning - we all humans - wherever we live, whatever color, race, gender, ethnicity or religion, or political alignments we have- primarily- we are human and we are related and interconnected, similarly, all biodiverse living being are our relatives and the physical structure
- including all ecosystems - of the planet is house for all of us combinedly). This notion, advocates that, each of the living species has the same rights of their survival as we human has, in this earth and its ecosystems. As we already witnessed that, disturbances of planet ecosystems (due anthropogenic disturbances in the planet ecosystems we are already facing climate change, biodiversity loss, sea liven rise, weather variations, flood, land slight, erosions, pollutions etc.) has direct negative impacts on human as well as to all living beings in the planet. Therefore, it is our responsibility to spread the philosophy of Bashudhaiva Kutumbakam and use our all expertise to protect or maintain the ecosystems where each of species can enjoy their existence.

As knowledge practitioners, it is our responsibility to advocate and to make aware to the all concerned stakeholders, that this planet does not belongs to only human it also equally belongs to the all living beings who are directly or indirectly related to us. Therefore, as scholars, our topmost priority should be to protect the planet and its biodiversity-ecosystems. In another words, we should first accept and realize that, if we human have the human rights of survival, then, why not other living being has no rights of enjoy their lives, since we share the same systems of the planet.

In my opinion, if we believe that, we are knowledgeable, educators, knowledge producers and practitioners; we should not influence by the greed, ego, anger, prejudice, and also should not limit ourselves on only I am right. We should not be in trap of within the individualistic bubbles; instead, need to realize that, we all are directly or indirectly connected within humans and other living being of the planet. We need to explore the ways of "how societies can remain in the harmonious relationships" as well as how we can maintain the harmonious relationships with nature and other living being, who share the same house for survival. We should/can begin this kind of relation - through the service to the humanity and extend that service to the other living beings by using our knowledge and wisdom. Knowledge is the key to open the reality of the problem and knowledge helps to realize or to understand the facts and wisdom is the proper utilization of acquired knowledge. As knowledge practitioner, we are aware that, we are by nature social beings and enjoy ourselves in society. Society can only be harmonious when all members of the society maintain the societal norms and values. Society can only remain healthy- when we respect each other, encourage each other and love each other and importantly if we have balanced resources to maintain the life support system of the society. This notion applies to the large house as well "Bashudhaiva Kutumbakam". It is kind of extended family - where all living beings share the same planet. Therefore, it is our responsibility, that each of the members can enjoy their part of resources. It is our responsibility to create the harmonious environment, where, live and let other live principles fully gets utilized.

Finally, I request to all scholars to utilize the acquired, learned, experienced and practiced knowledge which can help to create and maintain the harmonious relationships, within and beyond of human and nonhuman living beings. 


\section{Acknowledgements}

I thank to you all, who have been contributing by research, service, publications or other means to the world since we trapped under the Covid-19 regime. Especially thank you to scholarly contributors of every issues journals, wherever they have published, or being publishing in this serious time and thank to all who have shown that uncertainty does not stop to the knowledge producers, and to the all other scholars, who will be contributing in comings issues of the any scholarly journals, newspaper, TV shows etc. Once again, thank you to the editorial team for publishing my thoughts in your journal. I would also like to thank to my wife Prajita Bhandari, for encouraging to contribute for the society specially some thoughts of hope. Thank you.

\section{References}

Bhandari, M. P. (2019). “Bashudaiva Kutumbakkam"The entire world is our home and all living beings are our relatives. Why we need to worry about climate change, with reference to pollution problems in the major cities of India, Nepal, Bangladesh and Pakistan. Advances in Agriculture and Environmental Science, 2(1), 8-35. doi:10.30881/aaeoa.00019

Bhandari, M. P. (2019). Live and let other live - the harmony with nature/living beings-in reference to sustainable development (SD) - is contemporary world's economic and social phenomena is favorable for the sustainability of the planet in reference to India, Nepal, Bangladesh, and Pakistan? Advances in Agriculture and Environmental Science, 2(2), 37-57. doi:10.30881/aaeoa.00020

Bhandari, M. P. (2020). The phobia corona (COVID 19) - What can we do. Scientific Journal of BielskoBiala School of Finance and Law, 24(1), 5-7. doi:10.5604/01.3001.0014.0769

\section{Cite this article as:}

Bhandari, M. P. (2020). In the Covid-19 Regime - What Role Intellectual Society Can Play. International Journal of Science Annals, 3(2), 5-7. doi:10.26697/ijsa.2020.2.1

The electronic version of this article is complete. It can be found online in the IJSA Archive https://ijsa.culturehealth.org/en/arhiv and in the KRPOCH Publishing Repository https://ekrpoch.culturehealth.org/handle/lib/71 This is an Open Access article distributed under the terms of the Creative Commons Attribution License, which permits unrestricted use, distribution, and reproduction in any medium, provided the original work is properly cited (http://creativecommons.org/licenses/by/4.0/deed.en). 